\title{
Micropropagation of rare Scutellaria havanensis Jacq. and preliminary studies on antioxidant capacity and anti-cancer potential
}

\author{
Lani $\operatorname{Irvin}^{1}$, Yarelia Zavala Ortiz ${ }^{2}$, Kamila Rivera Rivera ${ }^{2}$, Brajesh Nanda Vaidya ${ }^{1}$, Samantha H \\ Sherman ${ }^{1}$, Juan A. Negrón Berríos ${ }^{2}$, Nirmal Joshee ${ }^{1}$, and Alok Arun ${ }^{2 *}$ \\ ${ }^{1}$ Agricultural Research Station, Fort Valley State University, Fort Valley, GA, USA \\ ${ }^{2}$ Institute of Sustainable Biotechnology, Inter American University of Puerto Rico, \\ Barranquitas, Puerto Rico, USA
}

*Corresponding author. Email address: alok_arun@br.inter.edu

\begin{abstract}
We report the development of in vitro propagation protocols through adventitious shoot induction pathway for a rare and medicinal Scutellaria havanensis. In vitro propagation studies using nodal explants showed MS medium supplemented with $10 \mu \mathrm{M}$ 6-Benzylaminopurine induced highest number of adventitious shoots in a time dependent manner. A ten - day incubation was optimum for shoot bud induction as longer exposures resulted in hyperhydricity of the explants and shoots induced. We also report preliminary evidence of Agrobacterium tumefaciens EHA105 - mediated gene transfer transiently expressing of green fluorescent protein in this species. Transformation studies exhibited amenability of various explant tissues, internode being the most receptive. As the plant has medicinal value, research was carried out to evaluate its potential antioxidant capacity and the efficacy of methanolic leaf extracts in curbing the viability of human colorectal cancer cell line HCT116. Comparative total polyphenol, and flavonoid content measurement of fresh and air dried leaf extract revealed that the fresh leaf extracts contain higher total polyphenol and flavonoid content. The HCT 116 cell viability assessed by colorimetric assay using a 3-(4, 5-dimethyl-thiazol-2-yl)-2, 5-diphenyltetrazolium bromide, showed a steady growth inhibition after 24 hours of incubation. Scanning Electron Microscopy of leaf surface revealed high density of glandular and non-glandular trichomes. This research provides basis for the conservation of this rare plant and future phytochemical screening and clinical research.
\end{abstract}

Keywords: Conservation, HCT 116 cells, polyphenol, trichomes 


\section{INTRODUCTION}

The genus Scutellaria (commonly skullcap or scullcap) belongs to plant family Lamiaceae (mint family). The genus is widely distributed and represented by about 400 species globally (Paton, 1990). More than 295 bioactive compounds have been isolated and identified in 35 species of Scutellaria (Shang et al., 2010). Pharmacological studies have confirmed that total extracts or isolated flavonoids from Scutellaria species possess anti-lipoperoxidation, anti-platelet, antiinflammatory (Lee et al., 2003), antitumor (Li-Weber, 2009; Parajuli et al., 2011; Dandawate et al., 2012), anticancer (Patel et al., 2013), neuroprotective (Gaire et al., 2012) antithrombotic, antioxidant (Huang et al., 2006; Vaidya et al., 2013), hepatoprotective, antibacterial (TayaraniNajarani et al., 2012), and antiviral (Shang et al., 2010) activities. A recent review details ethnobotanical knowledge surrounding various Scutellaria species from different parts of the world and current ongoing biomedical studies (Irvin et al., 2019). Extracts from various parts of Scutellaria species possess antitumor, hepatoprotective, antioxidant, antibacterial and antiviral effects (Wu et al., 2013). Baicalein, a phenolic flavonoid compound derived mainly from the root of $S$. baicalensis, resulted in a concentration-dependent inhibition of cell growth and induction of apoptotic cell death in human colon cancer cells (Hwan Kim et al., 2013; Havermann et al., 2013). Similarly, extracts of $S$. barbata have shown in vivo growth inhibitory effects in a number of cancers (Wang et al., 2012). Our recent studies indicate that methanolic leaf extracts of Scutellaria ocmulgee (SocL) have a potential for developing neoadjuvant therapy for metastatic NSCLC (nonsmall cell lung cancer) cells employing a zebra fish model (Wright et al., 2021).

Scutellaria havanensis Jacq. (Havana skullcap) is a rare species based on its restricted distribution. S. havanensis grows as a groundcover herb on limestone rocks and cliffs, at lower to middle elevations in Puerto Rico, Mona Island, and the Bahamas whereas in Florida, Cuba, and Hispaniola it grows in rocky pinelands (Liogier, 1995). It has been used to treat several disorders, including those related to the Central Nervous System (Sierra et al., 2013). The plant has been used for the treatment of scabies and as a diaphoretic and a febrifuge as an ethnomedicine (Marrero et al., 2012). Seeds are used against psoriasis, and sarcoptic mange (Austin, 2004). Phytochemical screening of extracts from aerial parts of S. havanensis reported the presence of flavonoids, coumarins, triterpenoids, steroids, alkaloids, free amine groups, sugars, quinones, resins and saponins (Marrero et al., 2012). In addition, twenty-five volatile compounds from the extract of 
aerial parts of $S$. havanensis were identified, $\beta$-caryophyllene $(75.6 \%)$ being the most prominent compound (Marrero et al., 2013). Studies on Scutellaria extracts have shown its role in oxidative stress associated to several human pathogenesis (Scheck et al., 2006; Hsieh et al., 2007; Bardakci et al., 2015). The methanol and chloroform extracts of $S$. havanensis leaves and stems contain high concentrations of flavonoids including bioactive wogonin. Wogonin in the chloroform extract indicated its specific anti-plasmodial effect with respect to mammalian cells and thus could be useful for the development of antimalarial alternatives (Valdez et al., 2016). These compounds are synthesized in glandular trichomes that serve the function of defense and source of valuable chemicals and are also used as taxonomic tools. Type of trichomes and their location and frequency on the various parts of a plant can be used to check secondary metabolite potential of a species/variety and can also assist in identifying adulterants in herbal biomass (Sherman et al., 2021).

As this is a rare plant, an efficient micropropagation protocol will assist conservation and further research on biotransformation for bioactive molecules. There are successful reports on the rapid multiplication and genetic transformation of many Scutellaria species (Cole et al., 2007; Joshee et al., 2007; Tascan et al., 2010; Brearley et al., 2014; Vaidya et al., 2016). It is evident from literature that the success of micropropagation is primarily dependent on the selection of explant and plant growth regulators used in the culture medium. As the secondary metabolite synthesis in medicinal plants is carried out in specialized structures called trichomes, fluorescent staining of secretory cells and structural details using scanning electron microscope (SEM) are also presented. We also report evaluation of antioxidant capacity in fresh and air dried leaf extracts which could be an important factor contributing to medicinal activity. We report preliminary results on the efficacy of methanolic extracts of $S$. havanensis leaves on steady growth inhibition of HCT 116 human colon cancer cells, as measured by MTT colorimetric assay. 


\section{MATERIALS AND METHODS}

\section{Micropropagation}

Plant material, explant and media preparation: S. havanensis plants were raised from seeds (Plant World Seeds, USA) in the greenhouse. Vigorously growing shoots were harvested and sterilized as reported earlier for Scutellaria ocmulgee (Vaidya et al., 2016) to initiate mother stock cultures to supply clean explants for experiments. Using single and two node sterilized explants, mother stock plants were raised in test tubes on MS (Murashige and Skoog, 1962) basal medium (PhytoTechnology, USA). MS medium was supplemented with $3 \%(\mathrm{w} / \mathrm{v})$ sucrose, $0.4 \%$ (w/v) gelling agent gelzan (PhytoTechnology, USA) and the $\mathrm{pH}$ was adjusted to 5.8-5.9 prior to autoclaving. Cultures were incubated in the culture room maintained at $25 \pm 2{ }^{\circ} \mathrm{C}$ and $60 \%$ relative humidity with $16 \mathrm{~h}$ photoperiod provided by cool white fluorescent lamps. To initiate shoot induction experiments, one node explants were obtained from in vitro grown stock plants. Shoot induction experiment comprised of a control and four $(0.05,0.5,5.0$, and $10 \mu \mathrm{M})$ cytokinin 6 benzylaminopurine (BAP) (PhytoTechnology, USA) treatments. Prior to autoclaving the shoot induction medium, $30 \mathrm{~g} \mathrm{~L}^{-1}$ sucrose and $4 \mathrm{~g} \mathrm{l}^{-1}$ gelzan (PhytoTechnology, USA) was added and $\mathrm{pH}$ was adjusted to 5.8-5.9. Autoclaving was carried out for $20 \mathrm{~min}$ at $121{ }^{\circ} \mathrm{C}$ and $15 \mathrm{psi}$. After sterilization, $12 \mathrm{~mL}$ of shoot induction medium was dispensed into petri dishes $(60 \mathrm{~mm}$ x $15 \mathrm{~mm}$; Fisher Scientific, USA). Four nodal explants were placed in a petri dish for each BAP treatment and a total of five petri dishes were inoculated per treatment. Cultures were incubated at $25 \pm 2{ }^{\circ} \mathrm{C}$ with a $16 \mathrm{~h}$ photoperiod. To understand optimum exposure of BAP required for shoot induction, explants were transferred to MS basal elongation médium from various treatments after $0,3,5,7$ 10 and 14 days. Four explants from each BAP treatments were transferred and induced buds were allowed to elongate on MS basal medium for 21 days. Number of elongated adventitious shoots were counted after 21 days and statistical analysis was carried out. Culture responses were observed using a microscope (Leica EZ4W, USA) and pictures were taken. Elongated shoots ranging 3-4 cm in length with 3-4 nodes were cut and transferred to MS medium supplemented with 5 uM IBA (índole butyric acid) for rooting. Rooted plantlets were acclimatized as per our lab protocol standardized for Scutellaria species (Brearley et al., 2014; Vaidya et al., 2016) and then transferred to greenhouse in pots for further growth, flowering and seed set. 
Agrobacterium tumefaciens mediated genetic transformation: Genetic transformation studies on S. havanensis were carried out as per Vaidya et al. (2016) with minor modifications. Agrobacterium tumefaciens EHA105 with binary plasmid pq35SGR (Li et al., 2004) was tested for agroinfection and transformation efficiency. This study was carried out to test agroinfection and regeneration potential of various explants (node, internode, and petiole) on the basis of green fluorescent protein expression. Agroinfection was carried out by submerging explants in the bacterial suspension $\left(\mathrm{OD}_{600}\right.$ of $0.2,0.3,0.4,0.6$, and 1.0) for 30 minutes with occassional swirl. Fifteen replicates for each type of explant were used at each bacterial density point. Explants were wounded by scratching on the surface to facilitate agroinfection. After agroinfection, explants were dabbed on sterile filter paper to remove excess bacteria and incubated for co - cultivation in the dark for $72 \mathrm{~h}$ at $26-28{ }^{\circ} \mathrm{C}$ on moist sterile filter papers. Explants were checked for transient GFP expression using Olympus microscope (BX 43, Olympus, USA) equipped with epifluorescence illumination and a camera (DP 72, Olympus, USA). After completion of co-cultivation period, explants with positive GFP expression were rinsed with two changes of washing solution (liquid MS containing $250 \mathrm{mg} \mathrm{L}^{-1}$ of antibiotics carbenicillin and cefotaxime) (Phytotechnology Lab, USA) for 30 min each time. After washing, explants were gently dried on sterile filter paper by wicking away excess fluid and transferred to selection plate that contained shoot induction medium (MS $+5 \mu \mathrm{M}$ BAP) supplemented with $250 \mathrm{mg} \mathrm{L}^{-1}$ carbenicillin and cefotaxime both. After few changes of selection plates, explants with positive GFP expression were transferred to MS $+5 \mu \mathrm{M}$ $\mathrm{BAP}+100 \mathrm{mg} \mathrm{L}^{-1}$ carbenicillin $+100 \mathrm{mg} \mathrm{L}^{-1}$ cefotaxime for regeneration. Explants with positive GFP expression were photographed at this point and plant regeneration work is in progress.

Fluorescent microscopy for Secondary metabolite in trichomes: For the detection of secretory nature of trichomes, natural product reagent was prepared (Heinrich et al., 2002) with 5\% aqueous solution of aluminum chloride (Fisher Scientific, MA, USA) and 0.05\% Diphenyl boric acid- $\beta$ ethylaminoester (DPBA) (Sigma Aldrich, MO, USA) in 10\% methanol (Burdick and Jackson, MI, USA). Leaves from greenhouse grown and tissue cultured plants were soaked in the stain for 5-10 min in dark and observed under fluorescent microscope (Olympus BX 43, Olympus, USA) equipped with a UV light source (X-Cite series 120 Q; Lumen Dynamics, MA, USA) and DP 72 camera). Secondary metabolites in the trichomes on the abaxial and adaxial leaf surfaces were observed using DAPI filter (with excitation light at $\lambda 386 \mathrm{~nm}$; emission $\lambda 490 \mathrm{~nm}$ ) under 
fluorescent microscope. Trichomes fluoresce with different shades of yellow or light green depending on the type of compound present. A yellow-orange fluorescence serves as identification of phenols as flavone compounds (Combrinck et al., 2007). Auto-fluorescence is diagnostic of flavonoids and depending on the structure, will fluoresce dark yellow, green or blue under UV365 nm light (Wagner and Bladt, 1996).

Scanning Electron Microscopy (SEM): The leaf samples were prepared for SEM as per the protocol optimized by Vaidya et al. (2016). The images were captured using variable pressurescanning electron microscope Hitachi 3400 NII (Hitachi High Technologies America, Inc., USA) at accelerating voltage of $10 \mathrm{kV}$ and working distance of $10 \mathrm{~mm}$ at Center for Ultrastructural Research (CURE), Agricultural Research Station, Fort Valley State University, GA.

\section{Preparation of leaf extracts}

Two samples of leaf tissues were randomly collected from mother plants, and cleaned, and weighed ( $2 \mathrm{~g}$ each). One sample was used for fresh extraction while the second sample was dried at room temperature $\left(35^{\circ} \mathrm{C}\right)$ in the dark for 7 days, weighed, and then used for extraction. For extraction, the leaves were homogenized with liquid nitrogen in a chilled $\left(-20{ }^{\circ} \mathrm{C}\right)$ mortar and pestle. The homogenized leaf powder was transferred to $125 \mathrm{~mL}$ Erlenmeyer flask containing 50 mL HPLC grade $100 \%$ methanol (Sigma-Aldrich, USA). The flasks were left overnight (18 h at $28.5^{\circ} \mathrm{C}$ ) in the dark on an orbital shaker at 200 RPM (Labline 3508 Dual Action Shaker; Marshall Scientific, USA). The suspension was then transferred to $50 \mathrm{~mL}$ Falcon tubes (BD, USA) to be centrifuged at 4000 RPM (5810 R; Eppendorf, USA) at $25^{\circ} \mathrm{C}$ for $40 \mathrm{~min}$. The supernatant was collected and the remaining pellet was extracted again for $1 \mathrm{~h}$, with $25 \mathrm{~mL}$ of methanol. After the second extraction, the two extracts were combined and the pellets were discarded. The combined extract was filtered through a double layer of Whatman ${ }^{\mathrm{TM}}$ filter paper No. 41 (GE Healthcare Life Sciences, UK) and stored in air tight $50 \mathrm{~mL}$ Falcon tubes at $4{ }^{\circ} \mathrm{C}$ in the dark, until further analysis.

\section{Biochemical assays}

a. Total polyphenol (TPP) content was determined by the Folin-Ciocalteu reagent (SigmaAldrich, USA) method (Lowry et al., 1951) as modified by Yi and Wetzstein (2010) and Vaidya et al. (2013) for the herbs in Lamiaceae family. Gallic acid (3, 4, 5-trihydroxybenzoic acid) (Sigma Life Science, USA) was used to develop standard curve as outlined by Singleton and Rossi (1965). 
A Multiskan GO Microplate Spectrophotometer (Thermo Fisher Scientific, USA) was used to read the extract solution absorbance at $765 \mathrm{~nm}$. For each sample, five replicates were measured at $20 \mathrm{~s}$ intervals in three different runs. Total phenolic content was expressed as mg gallic acid equivalent/g dry or fresh extract (GAE mg/g).

b. Total flavonoid content was evaluated using the aluminum chloride (Sigma-Aldrich, USA) colorimetric method (Chang et al., 2002; Vaidya et al., 2013). A standard solution (1 mg aluminum chloride/mL) was prepared by dissolving HPLC grade quercetin dihydrate (HWI ANALYTIK GMBH, Germany) in $80 \%$ ethanol (Sigma-Aldrich, USA). The standard curve was generated as per Vaidya et al. (2013). The test solutions included a mixture of $20 \mu \mathrm{L}$ of plant extracts with 60 $\mu \mathrm{L}$ of $95 \%$ ethanol, $4 \mu \mathrm{L}$ of $10 \%$ aluminum chloride, $4 \mu \mathrm{L}$ of $1 \mathrm{M}$ potassium acetate and $112 \mu \mathrm{L}$ of distilled water ( $200 \mu \mathrm{L}$ reaction mixture). These mixtures containing fresh and dry extracts were incubated at $25^{\circ} \mathrm{C}$ for $30 \mathrm{~min}$ and measurements were taken at absorbance of $415 \mathrm{~nm}$. The samples were run in triplicate in a succession. The blank was prepared without the addition of aluminum chloride. The absorbance data was plotted against total flavonoid content using standard curve generated by quercetin dehydrate (Sigma-Aldrich, USA).

c. Antioxidant capacity measurement. Trolox equivalent antioxidant capacity (TEAC) assay of a sample was calculated based on the inhibition of radical cation absorption exerted by the standard TROLOX solution (6-hydroxy-2, 5, 7, 8-tetramethy-chroman-2-carboxylic acid) (Sigma-Aldrich, USA), a vitamin E analogue (Davies et al., 1988). A 7 mM ABTS solution [2, 2'-azinobis (3ethylbenzothiazo-line-6-sulfonic acid) diammonium salt] (Sigma-Aldrich, USA) was mixed with $6.6 \mathrm{mg}$ of potassium persulfate (Sigma-Aldrich, USA) to make final concentration of $2.45 \mathrm{mM}$. This ABTS radical solution was incubated in the dark at $25^{\circ} \mathrm{C}$ for $16 \mathrm{~h}$, and then diluted with ethanol to get an optical density (OD) A $734=0.70 \pm 0.02$ with spectrophotometer in Multiskan ${ }^{\mathrm{TM}}$ GO Microplate using a polystyrene 96 wells microplate (Costar \#3628, Corning Inc., USA). Once the OD $\mathrm{A}_{734}=0.70 \pm 0.02$ was achieved, $180 \mu \mathrm{L}$ of ABTS was measured again. To the same measured ABTS, $20 \mu \mathrm{L}$ of a $S$. havanensis extract was added. The measured was conducted again after $6 \mathrm{~min}$ for the mixture. The measurements from all extracts were plotted against Trolox standards for percent inhibition at $6 \mathrm{~min}$. Calculation of antioxidant capacity was expressed as percent inhibition according to the equation: 
$\%$ Inhibition $=\left[\left(\mathrm{A}_{\text {Control }}-\mathrm{A}_{\text {Sample }}\right) / \mathrm{A}_{\text {Control }}\right] \times 100$

Where $A_{\text {Control }}$ is the absorbance of the control reaction (containing all reagents except the test compound), Asample is the absorbance of the test compound, and \% inhibition is the inhibition of ABTS absorbance by TROLOX.

\section{Culture of HCT 116 cell line}

The human colorectal carcinoma cell line HCT 116 was obtained from ATCC ${ }^{\circledR}$ (Number: CCL$\left.247^{\mathrm{TM}}\right)$ and was cultured in the McCoy's medium which had been supplemented with FBS (10\%, $\mathrm{v} / \mathrm{v}$ ) and penicillin-streptomycin solution $(1: 1000)$ provided by ATCC $^{\circledR}$ (Number: 30-2300). The cells $\left(5 \times 10^{3}\right)$ were seeded, in triplicate, into the 96 well plates and incubated under $5 \% \mathrm{CO}_{2}$ atmosphere at $37^{\circ} \mathrm{C}$ for $24 \mathrm{~h}$. Then the various dilutions of methanolic fresh and dry leaf extracts and control (without the extract), 1/2,1/10,1/100 and 1/1,000), were added to the cells for incubation periods of $3,24,48$ and $72 \mathrm{~h}$ at $37^{\circ} \mathrm{C}$ respectively.

\section{Cell viability by MTT colorimetric method}

Cell viability was assessed by using a 3-(4, 5-dimethyl-thiazol-2-yl)-2, 5-diphenyltetrazolium bromide (MTT) (Sigma-Aldrich, USA) -based colorimetric assay. Cells in 96-well plates (5000 cells/well) were exposed to various dilutions of fresh and dry extracts ( 0 as control, $100 \%, 1 / 10$, $1 / 100$ and 1/1,000), then incubated under $5 \% \mathrm{CO}_{2}$ enriched atmosphere at $37{ }^{\circ} \mathrm{C}$ for each incubation period. The $30 \mu \mathrm{L}$ MTT solution $(5 \mathrm{mg} / \mathrm{mL}$ in phosphate buffered saline) was added and further incubated for $4 \mathrm{~h}$ at $37^{\circ} \mathrm{C}$. After aspirating the supernatant from the wells, $200 \mu \mathrm{L}$ dimethyl sulfoxide (DMSO) were added to dissolve formazan crystals. The absorbance of each well was observed at $595 \mathrm{~nm}$ using the Multiskan ${ }^{\mathrm{TM}}$ GO Spectrophotometer (Thermo Fisher Scientific, USA). Finally, these results were confirmed by the Trypan Blue dye exclusion method (Louis and Siegel, 2011) using 1:1 cell/dye dilution, and results processed by the Countess ${ }^{\circledR}$ II FL Automated Cell Counter (Life Technologies, USA). The percentage of inhibition was calculated using to the following formula: 


$$
\begin{gathered}
\frac{\% \text { Inhibition }=100-(\text { mean absorbance of extract }) \times 100}{\text { Mean absorbance of positive control }} \\
\% \text { Viability }=100-\% \text { Inhibition }
\end{gathered}
$$

Data collection and Statistical analysis: All data are presented as means \pm SE for at least three replications for each sample. Statistical analysis was based on two way analysis of variance (ANOVA) and Tukey's post hoc mean separation test with results at $\mathrm{P} \leq 0.05$ level was considered not statistically significant. 


\section{RESULTS AND DISCUSSION}

\section{Micropropagation}

Among the various BAP treatments, $10 \mu \mathrm{M}$ BAP treatment with 10 days long incubation produced the highest number of adventitious shoots using nodal explants (Figure 1A) upon transfer to elongation medium for 21 days, (Table 1, Figure 1B,C). After incubating for various time points, cultures were transferred to MS basal elongation medium and adventitious shoots were allowed to elongate for 21 days. Control group at the most exhibited bud break with possible elongation of two axillary buds. As there were no adventitious shoots produced on explants in control treatment, number of adventitious shoots was kept zero across the board (Table 1). Elongated shoots rooted in MS basal medium and MS medium supplemented with IBA both, acclimatized and then finally transferred to pots containing potting soil and moved to the greenhouse (Figure 1D, E). Similar reports are available in Scutellaria species experimented for micropropagation (Cole et al., 2007; Joshee et al., 2007; Brearley et al., 2014). A prolific shoot induction protocol was optimized for Scutellaria ocmulgee using transverse thin cell layer cultures (tTCL) of leaf and stem explants which was helpful in generating transgenic plants (Vaidya et al., 2016). In this study both cytokinins, BAP and TDZ, were effective in producing high number of shoots.

\section{Optimization of agroinfection and co-cultivation}

Transient GFP expression was observed at the cut ends and wounded sites of the nodal, internodal segments and leaf segments. Transient GFP expression was observed in explants after 3 days of co-cultivation (Figure 1 F-H). A total of 78 replicates for each type of explants were used for five bacterial density treatments. In this preliminary experiment, internode explants registered highest infectivity on the basis of number of explants expressing transient GFP expression (50\%) followed by nodes $(35.89 \%)$ and petioles $(20.5 \%)$. It was interesting to note that $\mathrm{OD}_{600}=1$ of bacterial suspension was most effective treatment for all three types of explants recording $70 \%$ of internode and nodal and $50 \%$ of petioles expressing GFP. Another treatment $\mathrm{OD}_{600}=0.6$ was the next most effective treatment as it resulted in 50, 40, and 20\% infection and GFP expression in internode, node, and petiole explant, respectively. After co-cultivation the explants were transferred to shoot induction medium with $250 \mathrm{mg} / \mathrm{L}$ of antibiotics Carbenicillin and cefotaxime to eliminate Agrobacterium. Explants were screened for bacterial contamination and positive transient GFP 
expression daily. Thirty percent of the original explants retained transient GFP expression after 5 days. Leaf explants were difficult to maintain in the long run as they succumbed to Agrobacterium overgrowth. It is clear from the ultrastructure of leaf that due to extensive network of trichomes ${ }_{2}$ it is difficult to eradicate bacteria. Transient expression was evident at the cut ends of the nodal and internodal explants, especially when callusing occurred. More studies are needed to regenerate transgenic plants.

Total polyphenol content: The gallic acid standard curve showed a linear correlation between absorbance and gallic acid equivalents with $\mathrm{R}^{2}=0.9862$, by the Folin-Ciocalteu Reagent Method. Fresh and dried leaf extracts of $S$. havanensis showed differences in the total polyphenol content (Figure 2A). In fresh extracts, TPP results ranged from 45.64 to $59.77 \mathrm{mg} / \mathrm{g}$ gallic acid equivalent (GAE). In dried extracts, TPP content were lower and ranged from 30.96 to $47.43 \mathrm{mg} / \mathrm{g}$ GAE.

Flavonoid content: Standard curve to determine total flavonoid content by using as reference quercetin was linear $\left(\mathrm{R}^{2}=0.9961\right)$. Total flavonoid content of $S$. havanensis ranged between $129.16 \mu \mathrm{g} / \mathrm{mL}$ to $155.37 \mu \mathrm{g} / \mathrm{mL}$ in fresh leaf extracts. In dried leaf extracts, flavonoid content ranged from $103.74 \mu \mathrm{g} / \mathrm{mL}$ to $135.77 \mu \mathrm{g} / \mathrm{mL}$. The higher flavonoid content was observed in the fresh extract (Figure 2B).

Antioxidant capacity measurement: Antioxidant capacity was measured to dry and fresh extracts of $S$. havanensis, diluted 1:10, and using the Trolox Equivalent Antioxidant Capacity (TEAC) assay. The standard curve showed Trolox percent inhibition of ABTS radicals generated by persulfate oxidation $\left(\mathrm{R}^{2}=0.9986\right)$. A higher TEAC (Figure $2 \mathrm{C}$ ) was obtained in fresh extract $(33.68 \%)$ as compared to dry extract (15.48\%). Table 1 summarizes total polyphenol, flavonoid content, and antioxidant capacity of dry and fresh extracts of $S$. havanensis. In all cases the concentration of antioxidant phytochemicals is higher in fresh than in dry extracts.

Fresh and dry leaf extracts of the $S$. havanensis showed differences in the total polyphenol content. In fresh extracts, the TPP average result was $51.46 \mathrm{mg} / \mathrm{g}$ GAE and for dry extracts $41.23 \mathrm{mg} / \mathrm{g}$ GAE. However, the higher TPP content was recorded in the fresh extract (Figure 2A). Similar study on sixteen Scutellaria species exhibited higher polyphenol and flavanoid content in the fresh leaf extracts of 10 and 14 species respectively when compared with the extract obtained from dried leaves (Vaidya et al., 2013). The difference in polyphenol and flavonoid content between dry and 
fresh extracts could be associated to the thermal stability of these compounds. An increase of polyphenol decomposition and volatilization has been observed in plant extracts subjected to temperature increase (Felicity et al., 2011). Total flavonoid content of S. havanensis ranged between $129.162 \mu \mathrm{g} / \mathrm{mL}$ to $155.37 \mu \mathrm{g} / \mathrm{mL}$ in fresh leaf extracts. In dry leaf extracts, flavonoid content ranged from $103.74 \mu \mathrm{g} / \mathrm{mL}$ to $135.77 \mu \mathrm{g} / \mathrm{mL}$, suggesting various Scutellaria species depend on the thermostability of flavonoid groups during leaf drying and extract preparation (Kumar and Pandey, 2013). Previous studies indicate decreased concentrations of TPP during drying of sea buckthorn leaves at temperatures ranging from 50 to $100{ }^{\circ} \mathrm{C}$, and resulted in and oven- or microwave-drying of herb Phyllanthus amarus led to significant reductions in antioxidant property causing the highest decrease in total polyphenols (Yi and Wetzstein, 2011).

A higher antioxidant capacity on the basis of TEAC assay was observed in the fresh extracts (Figure 2C). A previous report using S. havanensis confirmed that fresh herb extraction shows higher concentration of these chemicals than the dried herb, due to heat effect and the instability of the latter with respect to flavonoids content (Marrero et al., 2015). Comparing the results of this study with those of Vaidya et al., 2013 for various Scutellaria species, we conclude, that fresh extracts $S$. havanensis showed a higher TPP content that the dry extract of $S$. albida. Furthermore, the flavonoid content of in both fresh and dry extracts in S. havanensis was higher than in other Scutellaria species, such as S. albida, S. altissima, S. costaricana, S. drummondi, S. elliptica, S. incana, S. integrifolia, S. lateriflora, S. ovata, S. scandens and S. suffrutescens. Also, S. havanensis shows a higher flavonoid content of the fresh extract when compared to Rosmarinus officinalis, which is a common herb with well-known high antioxidant potential that has been used as a standard for many years ago (Genena et al., 2008). The inhibition percent for both fresh and dried extracts was higher in $S$. havanensis compared with $S$. drummondii. In fresh extracts, $S$. havanensis showed a more inhibition than $S$. lateriflora, S. albida, S. elliptica, S. incana, S. integrifolia and S. ovata (Vaidya et al., 2013). These preliminary results indicate that $S$. havanensis tissues contain an above average content of antioxidants, when compared with many other Scutellaria species.

Fluorescent detection of glandular trichomes. DPBA staining clearly differentiated nonglandular and glandular trichomes (Figure $1 \mathrm{I}, \mathrm{J}$ ). It is clear that non-glandular trichomes and stalk 
of glandular trichomes do not fluoresce when exposed under UV light. Secretory apical cell that contains secondary metabolites, register a green, yellow, or orange image.

Scanning Electron Microscopy. The scanning electron micrographs reveal different types of trichomes on both adaxial and abaxial leaf surfaces (Figure $1 \mathrm{~K}, \mathrm{~L}$ ). The abaxial leaf surface has higher density of hirsute capitate trichomes, though large peltate glandular trichomes are also visible (Figure 1K). The adaxial surface contain multicellular disc like glandular peltate trichomes as well as multicellular capitate trichomes without glandular secretory vesicle (Figure 1L).

HCT 116 cell line viability. Cell viability was reduced when HCT 116 cells were incubated with $S$. havanensis extracts. Viability of HCT 116 cells was measured at different dilutions of $S$. havanensis dry and fresh extracts, during 3, 24, 48, and $72 \mathrm{~h}$ incubation periods and normalized with the viability of control cells. Significant difference analyzed by ANOVA $(p<0.05)$ in cell viability was obtained when using $1 / 100$ and 1/1000 of dilutions of either dried of fresh extracts. Best results were obtained with 1/100 dilution (Figure 3). Percentage inhibition of S. havanensis extracts on the growth of the cell line HCT 116 was observed as measured by the MTT assay. Percentage inhibition for dry and fresh extracts was $90 \%$ and $87 \%$ respectively (Figure 3 ).

Dry and fresh extracts of $S$. havanensis decreased the viability of the colorectal cancer cell line HCT 116. A significant decrease in cell viability (ANOVA, $p<0.05$ ) was observed in dry and fresh extracts, as compared with control cells. Consistent results were obtained with plant extracts diluted to 1:100. These findings suggest that both fresh and dry extracts of $S$. havanensis may contain anticancer phytochemicals that inhibit cell growth. These results are consistent with previous research, in which flavonoids and phenolics have been reported as a free radical scavenger and as an inducer of apoptosis in leukemia, lung cancer and colon adenocarcinoma cell lines (Ghasemzadeh et al., 2010). Previous studies showed that quercetin has anticancer activities and were able to inhibit cancer cell growth of malignant mesothelioma cells in vitro (Demiroglu et al., 2010). Baicalein, which is another flavonoid present in Scutellaria species, at doses that are toxic to malignant cells (Wu et al., 2013) have shown no effect on the viability of normal human prostate epithelial cells (Ma et al., 2005). Remarkably, wogonin treatment did not affect the viability of normal human prostate epithelial cells (Lee et al., 2008). No significant difference in cell viability was observed when using either dry or fresh extracts. Both extracts showed percent 
inhibition values greater than $70 \%$ after 3 hours. These results suggest that the potential anticancer substance is not affected by the slow drying procedure used in this work.

\section{CONCLUSION}

Predominant secondary metabolites from plants like polyphenols, and flavonoids have been studied for their potential use as therapeutic compounds. They have shown considerable antioxidant activity; inhibition of cancer cell growth; induction of apoptosis etc. Increasing populations, urbanization and deforestation, mostly anthropogenic activities, are responsible for the endangered and extinct status of many valuable plants. In vitro multiplication can help assist germplasm conservation. This study optimized in vitro protocols for the efficient multiplication of plants that can be utilized for the isolation of therapeutic compounds or can be scaled up to produce clean biomass for herbal supplement industry. Fresh and dried plant extracts both exhibited considerable antioxidant activity and when tested on cancer cell line HCT 116, dose dependent inhibition was evident.

\section{Acknowledgements}

NJ would like to thank Evans Allen grant GEOX 5220 that enabled ongoing Scutellaria research at Fort Valley State University. AA would like to thank NSF HSI STEM Grant (Award No. 1928792) for helping engage undergraduate student for the research. 


\section{LITERATURE CITED}

Acevedo, P., and Strong, M. T. (2012). Catalogue of Seed Plants of the West Indies (Vol. 93). D.C., Washington: SMITHSONIAN INSTITUTION SCHOLARLY PRESS.

Austin, D. (2004). Florida Ethnobotany (1 ed.). Florida : CRC Press.

Bardakci, H., Skaltsa, H., Milosevic, T., Lazari, D., Hadjipavlou, D., and Yesilada, E. (2015). Antioxidant activities of several Scutellaria taxa and bioactive phytoconstituents from Scutellaria hastifolia L. Industrial Crops and Products, 77, 196-203.

Brearley T. A., Vaidya B. N., Joshee N. (2014) Cytokinin, Carbon Source, and Acclimatization Requirements for in vitro Propagation of Scutellaria barbata D. Don and Scutellaria racemosa Pers. American Journal of Plant Science 5: 3662-3672.

Cole, I. B., P. K. Saxena, and S. J. Murch. 2007. Medicinal biotechnology in the genus Scutellaria. In Vitro Cell Dev Bio-Plant. 43: 318-327.

Combrinck, S.G, Du Plooy, W, McCrindle R. I, and Botha, B. M. (2007). Morphology and histochemistry of the glandular trichomes of Lippia scaberrima (Verbenaceae). Annals of Botany 99, 1111-1119.

Dandawate S, Williams L, Joshee N, Rimando AM, Mittal S, Thakur A, Lum L and Parajuli P. (2012). Scutellaria extract and wogonin inhibit tumor-mediated induction of $\mathrm{T}_{\text {reg }}$ cells via inhibition of TGF- $\beta 1$ activity. Cancer Immunol Immunother 61:701-711.

Demiroglu, A., Basara, B., Kilic, E., and Yanikkaya, G. (2010). The Investigation of Effects of Quercetin and Its Combination with Cisplatin on Malignant Mesothelioma Cells In Vitro. Journal of Biomedicine and Biotechnology, 1-7.

Encyclopedia of Life. (2013). Retrieved from Scutellaria havanensis: Havana Skullcap: http://eol.org/pages/578028/overview

Felicity, C., Hoye, C., and Fernandez, V. (2011). Influence of Heating on the Polyphenolic Content and Antioxidant Activity of Grape Seed Flour. Journal of Food Science, 76(6), 884-890.

Gaire, B. P., Young Ock, K., Zhen Hua, J., Juyeon Jin, P., Juyeon, P., and Hoyoung, C. (2012). Bioactivity-guided isolation of baicalein and wogonin from the root of Scutellaria baicalensis Georgi, and their neuroprotective effect against 4-VO induced global ischemic model in rat. SONSIK JOURNAL, 4, 11-15.

Genena, A., Hense, H., Smania, A., and De Souza, S. (2008). Rosemary (Rosmarinus officinalis) - a study of the composition, antioxidant and antimicrobial activities of extracts obtained with supercritical carbon dioxide. Ciencia e Tecnologia de Alimentos, 28(2), 463-469. 
Ghasemzadeh, A., Jaafar, H., and Rahmat, A. (2010). Antioxidant Activities, Total Phenolics and Flavonoids Content in Two Varieties of Malaysia Young Ginger (Zingiber officinale Roscoe). Molecules, 15, 4324-4333.

Harborne, J. B., and Williams, C. A. (2000). Advances in flavonoid research since 1992. Phytochemistry, 55, 481-504.

Heinrich, G., Pfeifhofer, H. W., Stanbentheiner, E. and Sawidis, T. (2002). Glandular hairs of Sigesbeckia jorullensis Kunth (Asteraceae): Morphology, histochemistry and composition of essential oil. Annals of Botany, 89, 459-469.

Hsieh, C.-J., Hall, K., Ha, T., Li, C., Krishnaswamy, G., and Chi, D. (2007). Baicalein inhibits IL$1 \beta$ - and TNF- $\alpha$-induced inflammatory cytokine production from human mast cells via regulation of the NF-kB pathway. Clinical and Molecular Allergy, 1-10.

Huang, W.-H., Lee, A.-R., and Yang, C.-H. (2006). Antioxidative and antiinflammatory activities of polyhydroxyflavonoids of Scutellaria baicalensis Georgi. Bioscience, Biotechnology Biochemistry, 70, 2371-2380.

Irvin, L., C. Jackson, A. L. Hill, R. Bajaj, C. Mahmoudi, B. N. Vaidya, and N. Joshee. 2019. Skullcaps (Scutellaria spp.): Ethnobotany and current research. In: Joshee, N., Dheckney, S. A., Parajuli, P. (eds.) Medicinal Plants: Farm to Pharmacy. Springer, Berlin, Heidelberg. Pp. 141-168.

Joshee, N, S. R. Mentreddy, and A. K. Yadav. 2007. Mycorrhizal fungi and growth and development of micropropagated Scutellaria integrifolia plants. Ind Crops Prod. 25. 169177.

Kumar, S., and Pandey, A. K. (2013). Chemistry and Biological Activities of Flavonoids: An Overview. The Scientific World Journal, 1-16.

Lee, D.-H., Kim, C., Zhang, L., and Lee, Y. J. (2008). Role of p53, PUMA, and Bax in wogonininduced apoptosis in human cancer cells. Biochemical Pharmacology, 75(10), 2020-2033.

Lee, H., Ok Kim, Y., Kim, H., Yeou Kim, S., Kim, Y., and Sook Noh, H. (2003). Flavonoid wogonin from medicinal herb is neuroprotective by inhibiting inflammatory activation of microglia. The FASEB Journal, 1-21.

Liogier, A. (1995). Descriptive Flora of Puerto Rico and Adjacent Islands: Spermatophyta Dicotyledoneae. Melastomataceae to Lentibulariaceae (Vol. 4). Puerto Rico: La Editorial, UPR.

Li, Z.J., Jayasankar S., and Gray D. J. (2004) Bi-directional duplex promoters with duplicated enhancers significantly increase transgene expression in grape and tobacco. Transgenic Research, 13:143-154. 
Li-Weber, M. (2009). New therapeutic aspects of flavones: the anticancer properties of Scutellaria and its main active constituents Wogonin Baicalein and Baicalin. Cancer Treatment Reviews, 35, 57-68.

Kristine S. Louis and Andre C. Siegel. (2011). Cell viability analysis using trypan blue: Manual and Automated Methods. In (Ed. Martin J. Stoddart), Mammalian Cell Viability: Methods and Protocols, Methods in Molecular Biology, vol. 740, DOI 10.1007/978-1-61779-1086_2, (C) Springer Science + Business Media, LLC.

Ma, Z., Otsuyama, K.-i., Liu, S., Abroun, S., Ishikawa, H., and Tsuyama, N. (2005). Baicalein, a component of Scutellaria radix from Huang-Lian-Jie-Du-Tang (HLJDT), leads to suppression of proliferation and induction of apoptosis in human myeloma cells. Blood Journal, 105(8), 3312-3318.

Marrero, D., Morales, C., González, V., Cuellar, A., and Salas, E. (2015). Selective and High Yield Isolation of Pure Wogonin from Aerial Parts of Scutellaria havanensis Jacq. International Journal of Pharmaceutical Sciences Review and Research, 30(2),104-108.

Marrero, D., Morales, C., González, V., Rodríguez, E., and Sierra, R. (2013). Volatile Constituents from Leaves of Endemic Scutellaria havanensis Jacq. in Cuba. J. Essential Oil Bearing Plants, 16, 368 - 371.

Marrero, D., Morales, C., Gónzález, V., Salas, E., De la Sierra, R., and Rodríguez, E. (2012). Phytochemical screening of Scutellaria havanensis Jacq. Revista Cubana de Plantas Medicinales. 17(4), 402-407.

Parajuli, P., N. Joshee, S. R. Chinni, A. M. Rimando, S. Mittal, S. Sethi and A. K. Yadav. 2011. Delayed growth of glioma by Scutellaria flavonoids involve inhibition of Akt, GSK-3 and NF-kB signaling. J Neurooncol. 101(1),15-24.

Patel, P., Joshee, N., Rimando, A., and Parajuli, P. (2013). Anti-cancer Scopes and Associated Mechanisms of Scutellaria Extract and Flavonoid Wogonin. Current Cancer Therapy Reviews, 9, 34-42.

Scheck, A. C., Perry, K., Hank, N. C., and Clark, D. (2006). Anticancer activity of extracts derived from the mature roots of Scutellaria baicalensis on human malignant brain tumor cells. BMC Complementary and Alternative Medicine, 6(27), 1-9.

Shang, X., Hea, X., Hea, X., Li, M., Zhanga, R., and Fana, P. (2010). The genus Scutellaria an ethnopharmacological and phytochemical review. Journal of Ethnopharmacology, 128, 279-313.

Sherman, S. H., B. N. Vaidya, and N. Joshee. 2021. Micromorphological studies in an anxiolytic medicinal plant, Scutellaria lateriflora L. J Food and Agricultural Research. 1(1): 1-14. 
Tascan, A., J. W. Adelberg, M. Tascan, A. Rimando, N. Joshee, and A. K. Yadav. 2010. Hyperhydricity and flavonoid content of Scutellaria species in vitro on polyester-supported liquid culture systems. HortSci. 45(11): 1723-1728.

Tayarani-Najarani, Z., Asili, J., Parsaee, H., Hadi Mousavi, S., Vadati, N., and Mirzaee, A. (2012). Wogonin and neobaicalein from Scutellaria litwinowii roots are apoptotic for HeLa cells. Brazilian Journal of Pharmacognosy, 22, 268-276.

United States Department of Agriculture. (2014). Scutellaria havanensis Jacq. Havana skullcap. Retrieved from Plants Database: http://plants.usda.gov/core/profile?symbol=SCHA

Vaidya, B. (2013) Antioxidant Potential, Conservation, and Reproductive Biology of Medicinal Scutellaria. M.S. Dissertation, Fort Valley State University, Fort Valley.

Vaidya, B. N., Brearley, T. A., and Joshee, N. (2014). Antioxidant capacity of fresh and dry leaf extracts of sixteen Scutellaria species. Journal of Medicinally Active Plants, 2(3-4), 42-49.

Vaidya, B. N., Jackson, C.L., Perry, Z. D., Dhekney, S. A., and Joshee, N. (2016) Agrobacteriummediated transformation of thin cell layer explants of Scutellaria ocmulgee Small: A rare plant with anti-tumor properties. Plant, Cell, Tissue and Organ Culture. 127 (1), 57-69.

Valdés, A F-C; Fidalgo LM; Ramos IS; Delange DM; Rico CLM; Martínez JM; and Cuéllar AC. (2016). Antiprotozoal screening of the Cuban native plant Scutellaria havanensis, Pharmaceutical Biology, 54:12, 3197-3202, DOI: 10.1080/13880209.2016.1216130

Wagner H, Bladt S. (1996). Plant drug analysis: a thin layer chromatographic atlas, 2nd edn. Heidelberg: Springer-Verlag.

Wang, T.-s., Wang, S.-q., and Xiao, D.-1. (2012). A review of phytochemistry and antitumor activity of a valuable medicinal species: Scutellaria barbata. Journal of Medicinal Plants Research, 6(26), 4259-4275.

Wollenweber, E. (1982). Flavones and flavonols. In: Harborne, J.B., Mabry, T. J. Eds. The flavonoids: advances in research. London, Chapman and Hall, pp. 189-259.

Wright RE III, Shahin L, Gogineni V, Hussain Z, Naeem A, Sadasivan S, Sinha I, Neely M, Michellhaugh SK., Mittal S, Joshee N, and Parajuli P. 2021. J Medicinally Active Plants 10, (1) : 32-41. DOI: https://doi.org/10.7275/ck6p-ej40

Wu, J.-Y., Tsai, K.-W., Li, Y.-Z., Chang, Y.-S., Lai, Y.-C., and Laio, Y.-H. (2013). Anti-bladdertumor effect of baicalein from Scutellaria baicalensis Georgi and its application in vivo. Evidence-Based Complementary and Alternative Medicine, 1-12.

Yi, W., and Wetzstein, H. (2011). Effects of Drying and Extraction Conditions on the Biochemical Activity of Selected Herbs. HortScience, 46(1), 70-73. 
Table 1. Adventitious shoot bud induction in the nodal explants of $S$. havanensis in response to the various concentration of cytokinin BAP

\begin{tabular}{|c|c|c|c|c|c|}
\hline \multirow{2}{*}{ Treatment } & \multicolumn{5}{|c|}{ Number of days in the shoot induction medium and number of shoots } \\
\hline & 3 & 5 & 7 & 10 & 14 \\
\hline \multirow{2}{*}{ MS (Control) } & \multicolumn{5}{|c|}{ Number of elongated adventitious shoots } \\
\hline & 0 & 0 & 0 & 0 & 0 \\
\hline $\mathrm{MS}+0.05 \mu \mathrm{M}$ BAP & $2.67 \pm 1.25^{\mathrm{c}}$ & $5.33 \pm 1.25^{\mathrm{c}}$ & $2.67 \pm 0.94^{\mathrm{c}}$ & $2.67 \pm 0.47^{\mathrm{c}}$ & $2.67 \pm 1.25^{\mathrm{cd}}$ \\
\hline $\mathrm{MS}+0.5 \mu \mathrm{M}$ BAP & $2.33 \pm 0.94^{\mathrm{d}}$ & $0 . \underline{0}$ & $4 \underline{0} \pm 2.83^{\mathrm{c}}$ & $9.33 \pm 4.78^{b}$ & $3.67 \pm 1.89^{\mathrm{c}}$ \\
\hline $\mathrm{MS}+5.0 \mu \mathrm{M}$ BAP & $0.67 \pm 0.94^{\mathrm{d}}$ & $3.33 \pm 2.87^{\mathrm{c}}$ & $4.33 \pm 0.47^{\mathrm{c}}$ & $4 \underline{0.0} \pm 2.94^{\mathrm{c}}$ & $5.33 \pm 1.25^{\mathrm{c}}$ \\
\hline $\mathrm{MS}+10.0 \mu \mathrm{M}$ BAP & $5.0 \pm 0.82^{\mathrm{c}}$ & $2.0 \pm 0.82^{\mathrm{d}}$ & $8.0 \pm 4.55^{\mathrm{bc}}$ & $14.67 \pm 1.25^{\mathrm{a}}$ & $* 1.0 \pm 0.82^{\mathrm{d}}$ \\
\hline
\end{tabular}

\section{*Hyperhydric cultures}

Statistical analysis was carried out using analysis of variance (ANOVA) for the top three explants in each treatment. The means between 21 different treatments were analyzed using Tukey's post hoc mean separation test and the treatments with the same letters are not significantly different $(\mathrm{P}<0.05)$ level when compared at each induction period for different BAP concentrations.. The control treatments contained no plant growth regulators. 



Figure 1. A. A nodal explant, B. A nodal explant in elongation medium with multiple shoots after 10 days incubation on MS medium $+10 \mu \mathrm{M}$ BAP, C. Fully grown, elongated plantlets on MS basal medium, D. Ex vitro plantlet in a potting medium under intermittent mist in the greenhouse. E. Hardened plant in the greenhouse, F, G, and H. GFP expression on the node, at the cut end of an internode, and wounded areas on S. havanensis leaf. I. Fluorescent staining differentiating non-glandular and glandular trichomes J. Fluorescent detection of secondary metabolites in glandular trichomes K. Scanning Electron Micrograph of abaxial leaf surface showing dense non-glandular trichomes. L. Glandular and non-glandular trichomes on the adaxial leaf surface. Yellow arrow: Non-glandular trichomes; White arrow: Glandular trichomes. 

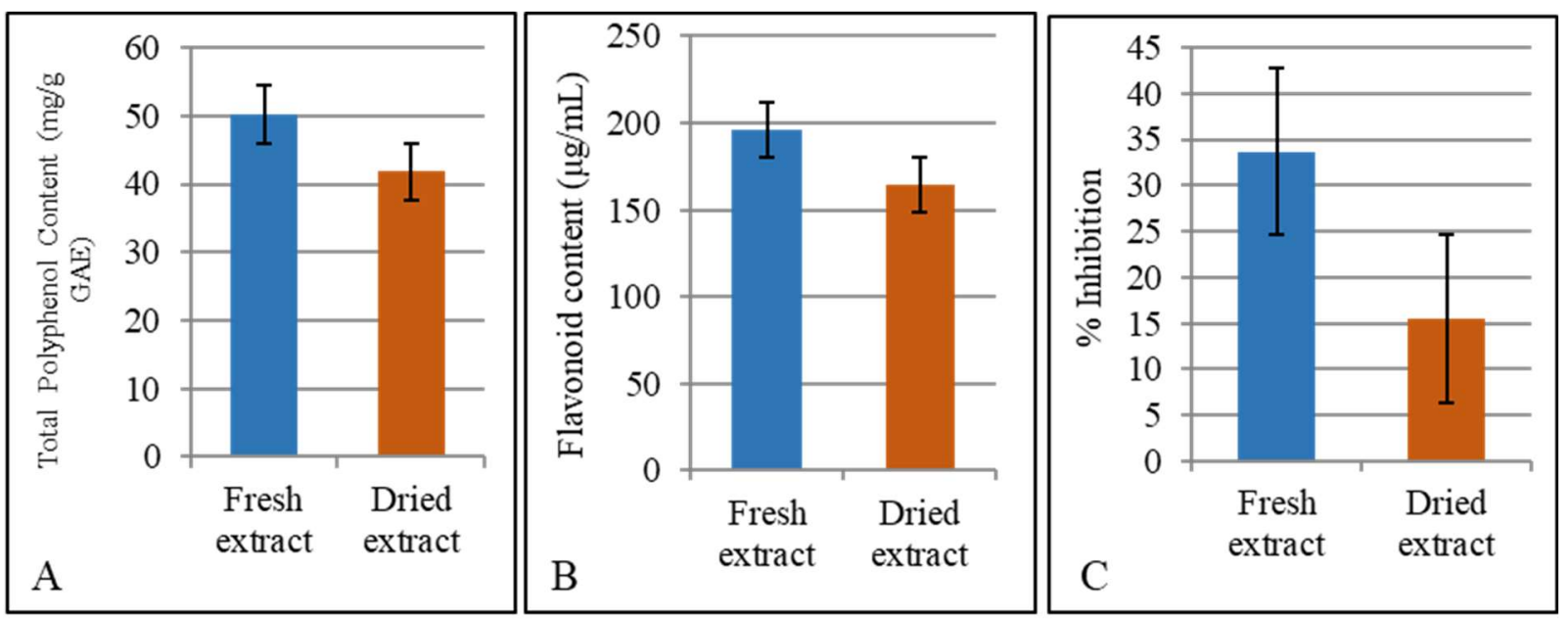

Figure 2. A. Total Polyphenol Content of fresh and dried extracts expressed as $\mathrm{mg} / \mathrm{g}$ of gallic acid equivalent (GAE mg/g), B. Estimation of Total Flavonoid Content of expressed as $\mu \mathrm{g} / \mathrm{mL}$, C. TROLOX Equivalent Antioxidant Capacity (TEAC) assay of dry and fresh extracts as percent inhibition. 

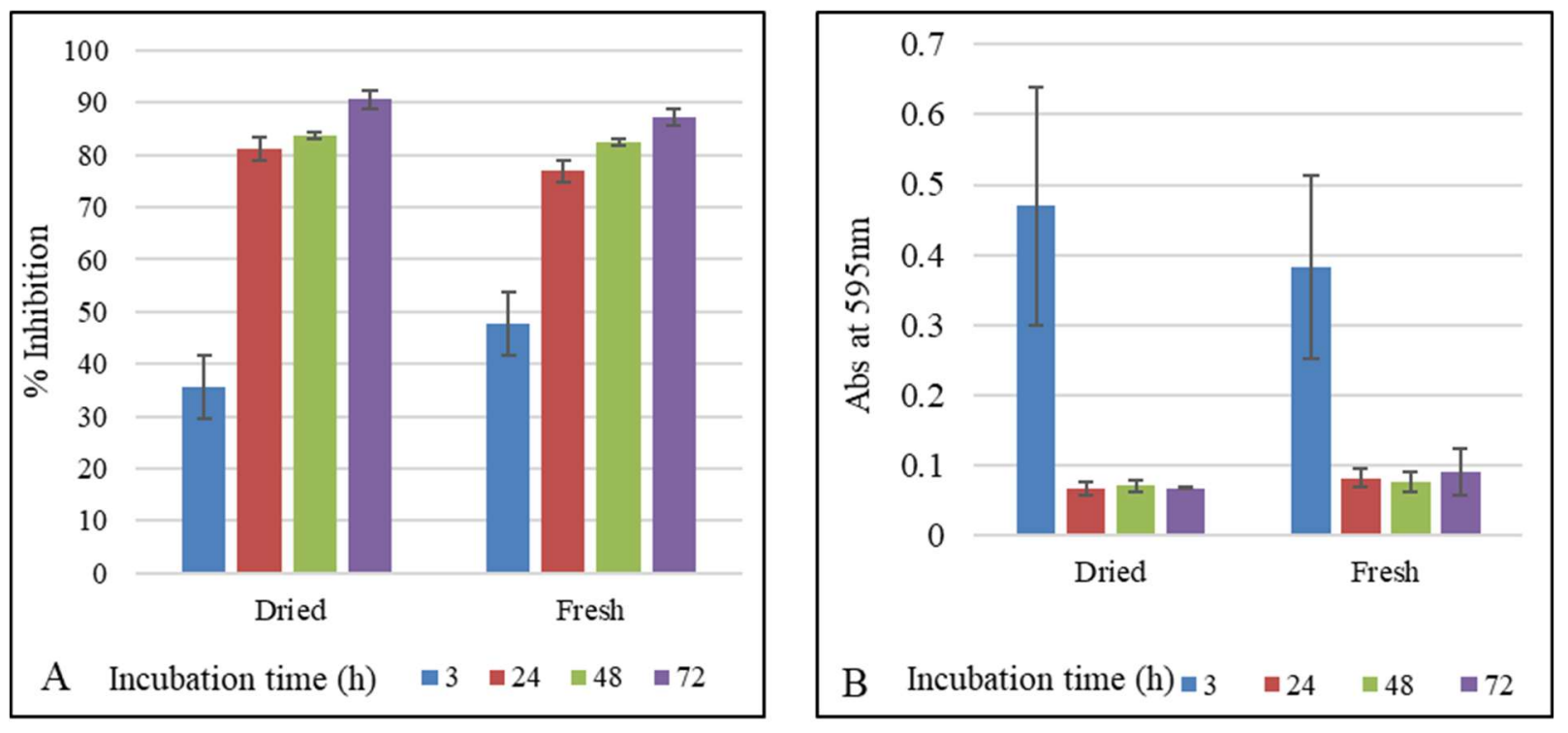

Figure 3. A: Inhibition percentage of HCT 116 Cell line in the presence of 1:100 dilutions of dry and fresh extracts at 3, 24, 48 and $72 \mathrm{~h}$ incubation times. B: Viability of HCT 116 cells using MTT assay in the presence of 1:100 dilution of dry and fresh leaf extracts at 3, 24, 48 and $72 \mathrm{~h}$ incubation times. 